\title{
Prelacteal and early formula feeding increase risk of infant hospitalisation: a prospective cohort study
}

\author{
Phung Nguyen (D) , ${ }^{1,2}$ Colin W Binns, ${ }^{2}$ Anh Vo Van Ha, ${ }^{2,3}$ Tan Khac Chu, ${ }^{2,4}$ \\ Luat Cong Nguyen, ${ }^{2,5}$ Dat Van Duong, ${ }^{2}$ Dung Van Do, ${ }^{1}$ Andy H Lee ${ }^{2}$
}

- Additional material is published online only. To view, please visit the journal online (http://dx.doi.org/ 10.1136archdischild-2019316937)

${ }^{1}$ Faculty of Public Health, University of Medicine and Pharmacy at Ho Chi Minh, Ho Chi Minh City, Vietnam

${ }^{2}$ School of Public Health, Curtin University Bentley Campus, Perth, Western Australia, Australia

${ }^{3}$ Faculty of Public Health, Pham Ngoc Thach University of Medicine, Ho Chi Minh City, Vietnam

${ }^{4}$ Faculty of Public Health, Hai Phong Medical University, Hai Phong, Vietnam

${ }^{5}$ National Immunization Program, National Institute of Hygiene and Epidemiology, Hanoi, Vietnam

\section{Correspondence to}

Ms Phung Nguyen, Faculty of Public Health, University of Medicine and Pharmacy at $\mathrm{Ho}$ Chi Minh, Ho Chi Minh City 700000, Vietnam;

nthphungytcc@ump.edu.vn

Received 29 January 2019 Revised 5 August 2019 Accepted 6 August 2019 Published Online First 15 September 2019

D) Check for updates

(C) Author(s) (or their employer(s)) 2020. No commercial re-use. See rights and permissions. Published by BMJ.

To cite: Nguyen P, Binns CW, Ha AVV, et al. Arch Dis Child 2020;105:122-126.

\begin{abstract}
Objective To ascertain the relationship between prelacteal feeding, early formula feeding and adverse health outcomes, especially hospitalisation during the first year of life.
\end{abstract}

Design Multicentre prospective cohort study.

Setting Six hospitals across three cities in Vietnam.

Patients A total of 2030 pregnant women were recruited at 24-28 weeks of gestation and followed up at hospital discharge, 1, 3, 6 and 12 months post partum.

Main outcome measures Rates of infant hospitalisation, diarrhoea and lower respiratory tract infection during the first 12 months.

Results For the final complete sample ( $n=1709,84 \%$ ), about one-quarter of the infants experienced diarrhoea $(25.5 \%)$ or were admitted to hospital with at least one episode (24.8\%), and almost half (47.6\%) the cohort contracted lower respiratory tract infection by 12 months. The prevalence of prelacteal feeding was high (56.5\%) while formula feeding was common (79.5\%) before hospital discharge, both of which increased the risks of adverse health outcomes particularly hospitalisation by approximately 1.5 -fold, with adjusted OR $(95 \% \mathrm{CI}) 1.43$ (1.09 to 1.88$)$ and 1.48 (1.07 to 2.05), respectively for these infants by 12 months, when compared with others who were exclusively breast fed.

Conclusions Prelacteal feeding and early formula feeding before hospital discharge are associated with higher risks of infection and hospital admission in Vietnamese infants. Support for exclusive breast feeding should be provided to mothers to avoid the adverse consequences of giving formula milk and prelateal foods.

\section{INTRODUCTION}

Respiratory infections and diarrhoea are the most common causes of death in children under 5 years of age, especially in low-income and middle-income countries. ${ }^{1-3}$ In Vietnam, the proportion of deaths among children under 5 years attributable to pneumonia is $10 \%-14 \%$ and diarrhoea is $5 \%-9 \% .^{14}$ Current evidence has shown a link between infant feeding types and hospitalisation for infectious diseases including respiratory infections and diarrhoea. ${ }^{5-11}$ For example, a cross-sectional study of Vietnamese infants $<5$ months in 2011 reported that early initiation and exclusive breast feeding were inversely associated with the prevalence of diarrhoea and acute respiratory infections. ${ }^{12}$ Another prospective cohort study of 1049 infants in 2015 concluded that exclusive breast feeding at 6 weeks of age reduced the odds of inpatient

\section{What is already known on this topic?}

- Giving prelacteal foods and formula milk to infants soon after birth is a common practice in Vietnam.

- The effects of early feeding method on infant illnesses have been documented in crosssectional surveys and birth cohort studies, but were mostly limited to 6 months after birth.

\section{What this study adds?}

- Prelacteal feeding and formula feeding before hospital discharge are associated with higher risks of infection and hospital admission during the first 12 months of life.

- Interventions to support exclusive breast feeding and to curtail the use of formula milk and prelacteal foods are needed to protect infants against infectious diseases.

admission for suspected pneumonia and diarrhoeal illness. $^{13}$

In Vietnam, high prevalence of prelacteal feeding and formula feeding has been reported in several studies. ${ }^{12} 1415$ However, the relationships between prelacteal and early formula feeding, infant illness and hospitalisation have not been investigated in detail. Therefore, the present prospective cohort study aimed to ascertain specifically the risk of hospitalisation within 1 year of birth for infants who were given prelacteal or early formula feeds. We hypothesise that infants fed with prelacteal foods or infant formula soon after birth experience higher rates of hospitalisation and childhood illnesses than their exclusively breastfed counterparts.

\section{MATERIALS AND METHODS \\ Design}

A multicentre prospective cohort study was undertaken between August 2015 and December 2017 at six hospitals across three cities of Vietnam. ${ }^{16}$ A total of 2030 pregnant women were recruited during their antenatal care visits between 24 and 28 weeks of gestation. After childbirth, participants were followed up at hospital discharge, then at 1, 3,6 and 12 months post partum. 


\section{Participants}

We recruited pregnant women who (1) were permanent residents in the study locations; (2) $\geq 18$ years of age; (3) at 24-28 weeks of gestation; (4) had a singleton pregnancy; (5) did not have any serious pre-existing health conditions according to medical records and (6) were able to read the information sheet and sign the consent form.

\section{Main exposures}

Breastfeeding practices were defined according to the WHO criteria. ${ }^{17}$ Prelacteal feeds are any foods (such as water, honey, formula milk and fruit juice) given before the onset of lactogenesis II, that is, the onset of copious breastmilk secretion occurring within 4 days of birth. ${ }^{18}$ Early formula feeding refers to a baby receiving any amount of any kind of reconstituted milk products or replacer after birth and before hospital discharge. In this study, prelacteal and early formula feeding were not mutually exclusive and recorded as binary variables (yes; no) at hospital discharge using the question "What was your baby's first feed after birth?" and "How are you feeding your baby?", respectively.

\section{Outcome measures}

The main outcomes were the presence (yes; no) of hospitalisation, diarrhoea and lower respiratory tract infection during the first 6 months and the first year of life. Hospitalisation refers to any inpatient admission of the infant due to illness or medical problems. Information on hospital admission (for any reason such as fever, jaundice, ear infection, diarrhoea and lower respiratory tract infection) was collected at the 1, 3, 6 and 12 months follow-up interviews using the question "Has your baby had any inpatient admission since the last interview?" Medical records were used to confirm such illness outcomes and hospital admission whenever feasible. All mothers were able to provide documentary evidence of admission to hospital and/or diagnosis from their medical invoices and infant health record books. A diarrhoea was defined as 'the passage of three or more loose or liquid stools per day, or more frequently than is normal for the individual'. ${ }^{19}$ Symptoms for a lower respiratory tract infection were 'at least one specific lower respiratory tract sign (fast or difficulty breathing, chest wall indrawing) and/or abnormal auscultatory findings (crackles/crepitations or bronchial breath sounds)' ${ }^{20}$ Although these two outcomes might overlap with the hospitalisation outcome for some cases, specific information on each admission episode was not collected, so that subcategorisation of the hospitalisation outcome was not feasible.

\section{Other variables}

Information on confounding factors such as maternal and sociodemographic characteristics, as suggested in the literature, ${ }^{891121}$ was collected at the baseline interview. Gestational diabetes was diagnosed following the criteria from the International Association of the Diabetes and Pregnancy Study Groups, with at least one glucose value above the threshold: fasting plasma glucose $\geq 5.1 \mathrm{mmol} / \mathrm{L}, 1$ hour plasma glucose $\geq 10.0 \mathrm{mmol} / \mathrm{L}, 2$ hours plasma glucose $\geq 8.5 \mathrm{mmol} / \mathrm{L}^{22}$. Variables related to birth were retrieved from medical records at hospital discharge, which included gestational age, gestational weight gain, caesarean section, infant gender, birth weight and admission to neonatal intensive care unit. Infant feeding methods after discharge were assessed through the question "How are you feeding your baby?" at the postpartum interviews. Any breastfeeding duration (weeks) was recorded at the interviews by asking "How old was your baby when you stopped breast feeding?"

\section{Statistical analysis}

In addition to descriptive statistics, group comparisons were made between infants with and without hospital admission during the first year, using $\chi^{2}$ test for categorical variables and t-test for continuous variables. Cumulative prevalence of the outcomes were computed at the four follow-up time points. Separate logistic regression analyses were then performed to determine the associations between prelacteal feeding, early formula feeding and the risks of hospitalisation, diarrhoea and lower respiratory tract infection during the first 6 months and the first year of life, with adjusted OR (AOR) and associated 95\% CIs to account for the effects of plausible confounding factors. Covariates included in the 12 logistic regression models were maternal age (years), occupation (working; not working), education level (secondary school or lower; high school graduate; college, university or above), parity $(0 ; 1 ; \geq 2)$, prepregnancy body mass index $\left(\mathrm{kg} / \mathrm{m}^{2}\right)$, gestational diabetes status (yes; no), gestational age (preterm $<37$ weeks; not preterm $\geq 37$ weeks), gestational weight gain (kg), caesarean section (yes; no), birth weight (g), infant gender (boy; girl) and newborn admission to neonatal intensive care unit (yes; no). To accommodate the potential effect of feeding practice after discharge, an additional covariate 'any breast feeding at 6 months (yes; no)' was included in the models for 6 months, whereas adjustment for the continuous 'any breastfeeding duration (weeks)' was made in the models for 12 months. All statistical analyses were undertaken using the SPSS package V.22 (IBM, Armonk, New York, USA).

\section{RESULTS}

Of the total 2030 pregnant women recruited at baseline, ${ }^{16} 297$ were lost-to-follow up and 24 mothers who experienced serious medical problems (HIV positive, $\mathrm{n}=2$; prepregnancy diabetes, $\mathrm{n}=6$; stillbirth, $\mathrm{n}=8$; termination of pregnancy, $\mathrm{n}=1$; infant death, $n=7$ ) were subsequently excluded, leaving $n=1709$ for data analysis (retention rate 84\%). No differences were found in maternal and sociodemographic characteristics between the final participants and the dropouts, except for maternal education $(\mathrm{p}<0.05)$.

Table 1 presents the characteristics of our cohort. Preterm births occurred in $4.2 \%$ of the sample, while over one-third (38.2\%) experienced caesarean section, and only 44 newborns $(2.6 \%)$ had been admitted to the neonatal intensive care unit. When comparing infants with and without hospitalisation during the first 12 months, the two groups were significantly different in terms of maternal education, infant gender and early feeding methods. In particular, the hospitalised infants had significantly higher rates of prelacteal feeding and formula feeding than their healthy counterparts $(61 \%$ and $83 \%$ vs $55 \%$ and $78 \%$, respectively) before hospital discharge. Overall, formula feeding was common (40\% at 1 month, $43 \%$ at 3 months and $66 \%$ at 6 months), but usually in conjunction with breast feeding, even though very few mothers exclusively breast fed their infants ( $18.8 \%$ at discharge and $<2 \%$ at 6 months).

Table 2 summarises the cumulative prevalence of hospitalisation, diarrhoea and lower respiratory tract infection from the four follow-ups of the cohort. About one-quarter of the infants experienced diarrhoea or were admitted to hospital with at least one episode during the first 12 months, while $14.6 \%$ of infants had admission(s) during their second 6 months of life. The prevalence of lower respiratory tract infection was very high, with almost half the cohort contracted the disease by 12 months.

Tables 3 and 4 present the associations between prelacteal feeding, early formula feeding and the adverse health outcomes 
Table 1 Characteristics of participants by hospitalisation status

\begin{tabular}{|c|c|c|c|c|}
\hline \multirow[b]{2}{*}{ Variables } & \multirow[t]{2}{*}{ Overall } & \multicolumn{2}{|c|}{ Hospitalisation during the first 12 months } & \multirow[t]{3}{*}{ P value* } \\
\hline & & Yes & No & \\
\hline Total, n (\%) & $1709(100)$ & $423(24.8)$ & $1286(75.2)$ & \\
\hline Maternal age (years), mean \pm SD & $27.5 \pm 5.3$ & $27.1 \pm 5.1$ & $27.6 \pm 5.3$ & 0.072 \\
\hline Occupation, n (\%) & & & & 0.816 \\
\hline Currently not working & $533(31.2)$ & $130(30.7)$ & $403(31.3)$ & \\
\hline Currently working & $1176(68.8)$ & $293(69.3)$ & $883(68.7)$ & \\
\hline Education level, n (\%) & & & & 0.031 \\
\hline Secondary school or lower & $574(33.6)$ & $146(34.5)$ & $428(33.3)$ & \\
\hline High school graduate & $445(26.0)$ & $127(30.0)$ & $318(24.7)$ & \\
\hline College/university or above & $690(40.4)$ & $150(35.5)$ & $540(42.0)$ & \\
\hline Parity, n (\%) & & & & 0.720 \\
\hline 0 & $655(38.3)$ & $160(37.8)$ & $495(38.5)$ & \\
\hline 1 & $636(37.2)$ & $164(38.8)$ & $472(36.7)$ & \\
\hline$\geq 2$ & $418(24.5)$ & $99(23.4)$ & $319(24.8)$ & \\
\hline Pre pregnancy BMI $\left(\mathrm{kg} / \mathrm{m}^{2}\right)$, mean $\pm \mathrm{SD}$ & $20.1 \pm 2.4$ & $20.1 \pm 2.5$ & $20.1 \pm 2.4$ & 0.945 \\
\hline Gestational diabetest, n (\%) & & & & 0.391 \\
\hline Yes & $373(21.8)$ & $86(20.3)$ & $287(22.3)$ & \\
\hline No & $1336(78.2)$ & $337(79.7)$ & $999(77.7)$ & \\
\hline Gestational age (weeks), n (\%) & & & & 0.214 \\
\hline Preterm: $<37$ & $71(4.2)$ & $22(5.2)$ & $49(3.8)$ & \\
\hline Not preterm: $\geq 37$ & $1638(95.8)$ & $401(94.8)$ & $1237(96.2)$ & \\
\hline Gestational weight gain $(\mathrm{kg})$, mean \pm SD & $13.0 \pm 4.0$ & $13.3 \pm 3.8$ & $13.0 \pm 4.0$ & 0.112 \\
\hline Caesarean section, $\mathrm{n}(\%)$ & & & & 0.784 \\
\hline Yes & $653(38.2)$ & $164(38.8)$ & $489(38.0)$ & \\
\hline No & $1056(61.8)$ & $259(61.2)$ & $797(62.0)$ & \\
\hline Infant gender, n (\%) & & & & $<0.001$ \\
\hline Boy & $875(51.2)$ & $249(58.9)$ & $626(48.7)$ & \\
\hline Girl & $834(48.8)$ & $174(41.1)$ & $660(51.3)$ & \\
\hline Birth weight $(\mathrm{g})$, mean \pm SD & $3146.2 \pm 395.0$ & $3120.3 \pm 427.7$ & $3154.7 \pm 383.4$ & 0.143 \\
\hline Admission to NICU, n (\%) & & & & 0.078 \\
\hline Yes & $44(2.6)$ & $16(3.8)$ & $28(2.2)$ & \\
\hline No & 1665 (97.4) & $407(96.2)$ & $1258(97.8)$ & \\
\hline Prelacteal feeding, n (\%) & $966(56.5)$ & $258(61.0)$ & $708(55.0)$ & 0.033 \\
\hline Early formula feeding, n (\%) & 1352 (79.1) & $350(82.7)$ & 1002 (77.9) & 0.034 \\
\hline
\end{tabular}

${ }^{*}$ From $\chi^{2}$ and t-tests.

†Based on International Association of the Diabetes and Pregnancy Study Groups criteria (2010).

BMI, body mass index; NICU, neonatal intensive care unit; SD, Standard deviation.

during the first 6 and 12 months, respectively, after adjusting for plausible confounding factors. The observed rates for all outcomes were higher among prelacteal-fed and early formula-fed infants. Both prelacteal and early formula feeding were apparently associated with hospitalisation and diarrhoea but not lower respiratory tract infection during the first 6 months of life (table 3). By 12 months, their risks of adverse health outcomes were almost 1.5 times higher than the exclusively breastfed infants, particularly for hospitalisation, with AOR (95\% CI) 1.43

Table 2 Cumulative prevalence of infant hospitalisation, diarrhoea and lower respiratory tract infection at 1, 3, 6 and 12 months

\begin{tabular}{lllll}
\hline & \multicolumn{4}{l}{ Prevalence (one or more episodes) } \\
\cline { 2 - 5 } Adverse health outcome & $\leq 1$ month & $\leq 3$ months & $\leq 6$ months & $\leq 12$ months \\
\hline Hospital admission, $\mathrm{n}(\%)$ & $55(3.2)$ & $125(7.3)$ & $241(14.1)$ & $423(24.8)$ \\
Diarrhoea, $\mathrm{n}(\%)$ & $45(2.6)$ & $120(7.0)$ & $256(15.0)$ & $435(25.5)$ \\
$\begin{array}{l}\text { Lower respiratory tract } \\
\text { infection, } \mathrm{n}(\%)\end{array}$ & $92(5.4)$ & $242(14.2)$ & $434(25.4)$ & $814(47.6)$ \\
\hline
\end{tabular}

(1.09 to 1.88 ) and 1.48 (1.07 to 2.05$)$, respectively (table 4). The online supplementary table shows the detailed results from fitting the 12 multivariable logistic regression models, each with a different set of significant factors and covariates.

\section{DISCUSSION}

This large prospective cohort study confirmed that both prelacteal feeds and early formula feeding before hospital discharge are associated with adverse infant health outcomes during their first year of life. The observed high prevalence of prelacteal feeding and early formula feeding before hospital discharge were consistent with previous cross-sectional studies in Vietnam which reported rates above 50\%. ${ }^{12} 1423$ A recent quasi-experimental study indicated over half the infants received prelacteal feeds, and formula milk was used as the first feed by $65.5 \%$ of the control group and $50 \%$ overall. $^{24}$

In Vietnam, respiratory diseases, bacterial and parasitic infections accounted for most hospital admissions in children. ${ }^{25}$ Compared with the our observed hospitalisation rate of $14.8 \%$ for all causes during the first 6 months, a previous cohort study 
Table 3 Association between prelacteal feeding, early formula feeding and adverse health outcomes during the first 6 months of life

\begin{tabular}{|c|c|c|c|c|c|c|c|c|c|}
\hline \multirow{2}{*}{$\begin{array}{l}\text { Feeding method } \\
\text { before hospital } \\
\text { discharge }\end{array}$} & \multicolumn{2}{|c|}{$\begin{array}{l}\text { Hospitalisation } \\
\text { (0-6 months) }\end{array}$} & \multirow[b]{2}{*}{$\begin{array}{l}\text { AOR* }^{*} \\
(95 \% \mathrm{Cl})\end{array}$} & \multicolumn{2}{|c|}{$\begin{array}{l}\text { Diarrhoea } \\
\text { (0-6 months) }\end{array}$} & \multirow[b]{2}{*}{$\begin{array}{l}\text { AOR* } \\
(95 \% \mathrm{Cl})\end{array}$} & \multicolumn{2}{|c|}{$\begin{array}{l}\text { Lower respiratory tract } \\
\text { infection ( } 0-6 \text { months) }\end{array}$} & \multirow[b]{2}{*}{$\begin{array}{l}\mathrm{AOR}^{*} \\
(95 \% \mathrm{Cl})\end{array}$} \\
\hline & $\begin{array}{l}\text { Yes } \\
\text { n (\%) }\end{array}$ & $\begin{array}{l}\text { No } \\
\mathrm{n}(\%)\end{array}$ & & $\begin{array}{l}\text { Yes } \\
\mathrm{n}(\%)\end{array}$ & $\begin{array}{l}\text { No } \\
\mathrm{n}(\%)\end{array}$ & & $\begin{array}{l}\text { Yes } \\
\text { n (\%) }\end{array}$ & $\begin{array}{l}\text { No } \\
\mathrm{n}(\%)\end{array}$ & \\
\hline \multicolumn{10}{|l|}{ Prelacteal feeding } \\
\hline Yes & $148(15.3)$ & $818(84.7)$ & 1.44 (1.02 to 2.03 ) & 166 (17.2) & $800(82.8)$ & 1.73 (1.25 to 2.41$)$ & $246(25.5)$ & $720(74.5)$ & 0.85 (0.65 to 1.12 ) \\
\hline No & $93(12.5)$ & 650 (87.5) & 1 & $90(12.1)$ & $653(87.9)$ & 1 & $188(25.3)$ & $555(74.7)$ & 1 \\
\hline \multicolumn{10}{|l|}{ Formula feeding } \\
\hline Yes & 197 (14.6) & $1155(85.4)$ & 1.39 (0.92 to 2.10$)$ & 215 (15.9) & 1137 (84.1) & 1.50 (1.02 to 2.21$)$ & 350 (25.9) & $1002(74.1)$ & 1.00 (0.74 to 1.37$)$ \\
\hline No & $44(12.3)$ & $313(87.7)$ & 1 & $41(11.5)$ & $316(88.5)$ & 1 & $84(23.5)$ & $273(76.5)$ & 1 \\
\hline
\end{tabular}

*Adjusted for maternal age (years), occupation (currently not working; currently working), education level (secondary school or lower; high school graduate; college/university or above), parity $(0 ; 1 ; \geq 2)$, prepregnancy body mass index $\left(\mathrm{kg} / \mathrm{m}^{2}\right)$, gestational diabetes (yes; no), gestational age (preterm; not preterm), gestational weight gain $(\mathrm{kg})$, caesarean section (yes; no), infant gender (boy; girl), birth weight (g), admission to neonatal intensive care unit (yes; no) and any breast feeding at 6 months (yes; no). The models only included those with complete follow-up data for 12 months $(n=1709)$.

$A O R$, adjusted $\mathrm{OR} ; \mathrm{Cl}$, confidence interval.

with 6 months follow-up found $8.8 \%$ and $4 \%$ of infants required inpatient admission for suspected pneumonia and diarrhoeal illness, respectively. ${ }^{13}$ The prevalence of diarrhoea and acute respiratory infection among infants $0-5$ months (during the last 2 weeks) was $5.3 \%$ and $24.5 \%$, respectively, from another crosssectional study in Vietnam. ${ }^{12}$ These rates appeared to be comparable to our cumulative data at the 6-month follow-up (15\% and 25.4\%; table 2). Finding from a cohort study in Maldives also showed a large proportion of infants $(35.5 \%)$ had diarrhoea and acute respiratory tract infection (30.2\%) 6 months after birth. ${ }^{9}$

The present study found prelacteal and early formula feeding before hospital discharge are associated with adverse infant health outcomes, especially hospitalisation and lower respiratory tract infection. Data from a cross-sectional study in Vietnam similarly suggested that babies fed with prelacteal foods are more susceptible to acute respiratory illness. ${ }^{12}$ The observed marginal association between early formula feeding and diarrhoea was also consistent with the result from a nationwide longitudinal survey of Japanese children. ${ }^{11}$ Moreover, formula feeding during the first 3 days after birth was found to be associated with increased infant formula feeding and early breastfeeding cessation. $^{23}$ Another study from Brazil concluded that hospitalisation contributed to the interruption of exclusive breast feeding and the introduction of infant formula during hospitalisation. ${ }^{26}$ Breastmilk is known to have immunological protection against infection. On the other hand, provision of prelacteal foods and formula milk during the first few days of life can increase the infant's exposure to environmental contaminants from non-breastmilk supplements and change the microbiome as a result, ${ }^{27} 28$ thereby increasing their risk of childhood illnesses.

A major strength of this study was the multicentre prospective cohort study design with a large sample size, which enabled the longitudinal repeated measures of infant health outcomes with follow-up interviews at 1, 3, 6 and 12 months after birth; unlike previous cross-sectional surveys or birth cohort studies in Vietnam with limited follow ups (typically 6 months). Moreover, the final retention rate was high at $84 \%$, and data were collected from six hospitals in both north and south of the country, thus representative of the urban population in Vietnam. To overcome the limitation concerning the self-reported nature of the outcome variables, all reported illness symptoms by the mothers were confirmed with medical records whenever feasible, otherwise the diagnoses were reviewed and assigned by a paediatrician following the standard protocol. Consequently, the observed hospitalisation rates might likely overestimate the actual prevalence of childhood illnesses attributable to the adverse feeding methods, but the same magnitude of bias would also apply to the exclusively breastfed infants. Therefore, additional analyses were undertaken for diarrhoea and lower respiratory tract infection to confirm the effects of prelacteal and early formula feeding. The infant health outcomes were classified as binary variables which did not distinguish infants with single and multiple episodes of illness. The data were analysed using information from participants who completed the 12-month postpartum interview,

Table 4 Association between prelacteal feeding, early formula feeding and adverse health outcomes during the first year of life

\begin{tabular}{|c|c|c|c|c|c|c|c|c|c|}
\hline \multirow{2}{*}{$\begin{array}{l}\text { Feeding method } \\
\text { before hospital } \\
\text { discharge }\end{array}$} & \multicolumn{2}{|c|}{$\begin{array}{l}\text { Hospitalisation } \\
\text { (0-12 months) }\end{array}$} & \multirow[b]{2}{*}{$\begin{array}{l}\text { AOR* } \\
(95 \% \mathrm{CI})\end{array}$} & \multicolumn{2}{|c|}{$\begin{array}{l}\text { Diarrhoea } \\
\text { (0-12 months) }\end{array}$} & \multirow[b]{2}{*}{$\begin{array}{l}\text { AOR* } \\
(95 \% \mathrm{Cl})\end{array}$} & \multicolumn{2}{|c|}{$\begin{array}{l}\text { Lower respiratory tract } \\
\text { infection (0-12 months) }\end{array}$} & \multirow[b]{2}{*}{$\begin{array}{l}\text { AOR* } \\
(95 \% \mathrm{CI})\end{array}$} \\
\hline & $\begin{array}{l}\text { Yes } \\
\mathrm{n}(\%)\end{array}$ & $\begin{array}{l}\text { No } \\
\mathrm{n}(\%)\end{array}$ & & $\begin{array}{l}\text { Yes } \\
\mathrm{n}(\%)\end{array}$ & $\begin{array}{l}\text { No } \\
\mathrm{n}(\%)\end{array}$ & & $\begin{array}{l}\text { Yes } \\
\mathrm{n}(\%)\end{array}$ & $\begin{array}{l}\text { No } \\
\mathrm{n}(\%)\end{array}$ & \\
\hline \multicolumn{10}{|l|}{ Prelacteal feeding } \\
\hline Yes & $258(26.7)$ & $708(73.3)$ & 1.43 (1.09 to 1.88$)$ & $271(28.0)$ & 695 (71.9) & 1.56 (1.19 to 2.05 ) & $504(52.2)$ & $462(47.8)$ & 1.50 (1.18 to 1.90$)$ \\
\hline No & $165(22.2)$ & $578(77.8)$ & 1 & $164(22.1)$ & 579 (77.9) & 1 & $310(41.7)$ & $433(58.3)$ & 1 \\
\hline \multicolumn{10}{|l|}{ Formula feeding } \\
\hline Yes & $350(25.9)$ & $1002(74.1)$ & 1.48 (1.07 to 2.05$)$ & $357(26.4)$ & $995(73.6)$ & 1.37 (1.00 to 1.87 ) & $672(49.7)$ & $680(50.3)$ & 1.41 (1.08 to 1.83$)$ \\
\hline No & $73(20.4)$ & $284(79.6)$ & 1 & 78 (21.9) & $279(78.1)$ & 1 & $142(39.8)$ & $215(60.2)$ & 1 \\
\hline
\end{tabular}

*Adjusted for maternal age (years), occupation (currently not working; currently working), education level (secondary school or lower; high school graduate; college/university or above), parity $(0 ; 1 ; \geq 2)$, prepregnancy body mass index $\left(\mathrm{kg} / \mathrm{m}^{2}\right)$, gestational diabetes (yes; no), gestational age (preterm; not preterm), gestational weight gain $(\mathrm{kg})$, caesarean section (yes; no), infant gender (boy; girl), birth weight (g), admission to neonatal intensive care unit (yes; no) and any breastfeeding duration (weeks). The models only included those with complete follow-up data for 12 months $(n=1709)$.

$\mathrm{AOR}$, adjusted $\mathrm{OR} ; \mathrm{Cl}$, confidence Interval. 
instead of adjustment of follow-up time for the entire cohort. Information on non-inpatient admission was not recorded, even though it might be a confounding factor for a subsequent inpatient admission. Finally, details of formula milk feeding such as intensity and duration before hospital discharge were not collected to avoid subject burden, which posed as another limitation of our study.

In conclusion, prelacteal feeding and early formula feeding are associated with elevated risks of hospitalisation, diarrhoea and lower respiratory tract infection. Given that relationships have been identified between paediatricians and formula milk companies, ${ }^{29}$ it is important to promote exclusive breast feeding and to educate women during their pregnancy about the adverse consequences of giving prelateal foods. Extra support should be available to mothers who have difficulties to initiate breast feeding, and to overcome their reliance on infant formula as a substitute for breastmilk.

Acknowledgements The authors would like to thank all participants of this study, the hospitals and data enumerators for their support in data collection.

Contributors PN: recruited patients, analysed and interpreted data, drafted the manuscript. CWB and AHL: conceptualised and designed the study, supervised the overall study conduct and analysis. AVVH, TKC, LCN: enrolled patients and interpreted data. DaVD and DuVD: provided technical support, supervised the overall study conduct and analysis. All authors critically revised and approved the final manuscript.

Funding This study was partially supported by Curtin University, Perth, Western Australia.

Competing interests None declared.

Patient consent for publication Not required.

Ethics approval This study was approved by the Hai Phong University of Medicine and Pharmacy Human Research Ethics Committee (approval no. 05/PHUMPRB), and the Curtin University Human Research Ethics Committee (approval no. HR32/2015).

Provenance and peer review Not commissioned; externally peer reviewed.

Data availability statement No data are available.

ORCID iD

Phung Nguyen http://orcid.org/0000-0001-8590-7637

\section{REFERENCES}

1 United Nations Children's Fund. One is too many: ending child deaths from pneumonia and diarrhoea, 2016. Available: https://www.unicef.de/blob/127260/728c 481d8b323fe15e58244179f11087/one-is-too-many-report-data.pdf [Accessed on 1 Aug 2018].

2 GBD 2016 Mortality Collaborators. Global, regional, and national under-5 mortality, adult mortality, age-specific mortality, and life expectancy, 1970-2016: a systematic analysis for the global burden of disease study 2016. Lancet 2017;390:1084-150.

$3 \mathrm{Kyu} \mathrm{HH}$, Pinho C, Wagner JA, et al. Global and national burden of diseases and injuries among children and adolescents between 1990 and 2013: findings from the global burden of disease 2013 study. JAMA Pediatr 2016;170:267-87.

4 Nhung NTT, Long TK, Linh BN, et al. Estimation of Vietnam national burden of disease 2008. Asia Pac J Public Health 2014;26:527-35.

5 Hengstermann S, Mantaring JBV, Sobel HL, et al. Formula feeding is associated with increased hospital admissions due to infections among infants younger than 6 months in Manila, Philippines. J Hum Lact 2010;26:19-25.
6 Bahl R, Frost C, Kirkwood BR, et al. Infant feeding patterns and risks of death and hospitalization in the first half of infancy: multicentre cohort study. Bull World Health Organ 2005;83:418-26.

7 Oddy WH, Kickett-Tucker C, De Maio J, et al. The association of infant feeding with parent-reported infections and hospitalisations in the West Australian Aboriginal child health survey. Aust N Z J Public Health 2008;32:207-15.

8 Fisk CM, Crozier SR, Inskip HM, et al. Breastfeeding and reported morbidity during infancy: findings from the Southampton women's survey. Matern Child Nutr 2011;7:61-70

9 Raheem RA, Binns CW, Chih HJ. Protective effects of breastfeeding against acute respiratory tract infections and diarrhoea: findings of a cohort study. J Paediatr Child Health 2017;53:271-6.

10 Payne S, Quigley MA. Breastfeeding and infant hospitalisation: analysis of the UK 2010 infant feeding survey. Matern Child Nutr 2017;13. doi:10.1111/mcn.12263. [Epub ahead of print: 24 Mar 2016].

11 Yamakawa M, Yorifuji T, Kato T, et al. Long-Term effects of breastfeeding on children's hospitalization for respiratory tract infections and diarrhea in early childhood in Japan. Matern Child Health J 2015;19:1956-65.

12 Hajeebhoy N, Nguyen PH, Mannava P, et al. Suboptimal breastfeeding practices are associated with infant illness in Vietnam. Int Breastfeed J 2014;9:12.

13 Hanieh S, Ha TT, Simpson JA, et al. Exclusive breast feeding in early infancy reduces the risk of inpatient admission for diarrhea and suspected pneumonia in rural Vietnam: a prospective cohort study. BMC Public Health 2015;15:1166.

14 Nguyen PH, Keithly SC, Nguyen NT, et al. Prelacteal feeding practices in Vietnam: challenges and associated factors. BMC Public Health 2013;13:932.

15 United Nations Population Fund. Viet Nam midwifery report, 2017.

16 Nguyen CL, Nguyen PTH, Chu TK, et al. Cohort profile: maternal lifestyle and diet in relation to pregnancy, postpartum and infant health outcomes in Vietnam: a multicentre prospective cohort study. BMJ Open 2017;7:e016794.

17 World Health Organization. Indicators for assessing infant and young child feeding practices: part 1-Definition: conclusions of a consensus meeting held 6-8 November 2007 in Washington D.C, 2008. Available: http://apps.who.int/iris/bitstream/10665/ 43895/1/9789241596664_eng.pdf [Accessed on 5 Apr 2018].

18 Neville MC, Morton J. Physiology and endocrine changes underlying human lactogenesis II. J Nutr 2001;131:3005S-8.

19 World Heatlh Organization. Diarrhoea. Available: http://www.who.int/topics/ diarrhoea/en/ [Accessed on 5 August 2015].

20 Roth DE, Caulfield LE, Ezzati M, et al. Acute lower respiratory infections in childhood: opportunities for reducing the global burden through nutritional interventions. Bull World Health Organ 2008;86:356-64.

21 Duijts L, Jaddoe VWV, Hofman A, et al. Prolonged and exclusive breastfeeding reduces the risk of infectious diseases in infancy. Pediatrics 2010;126:e18-25.

22 Metzger BE, Gabbe SG, Persson B, et al. International association of diabetes and pregnancy study groups recommendations on the diagnosis and classification of hyperglycemia in pregnancy: response to Weinert. Diabetes Care 2010;33:e98-82.

23 Nguyen TT, Withers $M$, Hajeebhoy $N$, et al. Infant formula feeding at birth is common and inversely associated with subsequent breastfeeding behavior in Vietnam. J Nutr 2016;146:2102-8.

24 Bich TH, Hoa DTP, Ha NT, et al. Father's involvement and its effect on early breastfeeding practices in Viet Nam. Matern Child Nutr 2016;12:768-77.

25 Nguyen NTT, Dien TM, Schindler C, et al. Childhood hospitalisation and related deaths in Hanoi, Vietnam: a tertiary hospital database analysis from 2007 to 2014. BMJ Open 2017;7:e015260.

26 Souza EL, Silva LR, Sá ACS, et al. [Impact of hospitalization on breastfeeding practices in a pediatric hospital in Salvador, Bahia State, Brazill. Cad Saude Publica 2008;24:1062-70

27 Gribble KD. Mechanisms behind breastmilk's protection against, and artificial baby milk's facilitation of, diarrhoeal illness. Breastfeed Rev 2011;19:19-26.

28 Gribble KD, Hausman BL. Milk sharing and formula feeding: infant feeding risks in comparative perspective? Australas Med J 2012;5:275-83.

29 Wright CM, Waterston AJR. Relationships between paediatricians and infant formula milk companies. Arch Dis Child 2006;91:383-5. 